\title{
Electrophysiological effects of L 9394 (benzoyl-indolizine) in man
}

\author{
A. WALEFFE, A. BORDALO ${ }^{1}$, P. BRUNINX, H. J. J. WELLENS 2 , AND \\ H. E. KULBERTUS \\ From the Laboratory of Electrocardiology, Institute of Medicine, University of Liege, Belgium; \\ and the Department of Cardiology, University of Limburg, Maastricht, The Netherlands
}

SUMMARY The electrophysiological effects of L 9394 (benzoyl-indolizine), a substance chemically related to amiodarone, but devoid of iodine atoms, were investigated by programmed electrical stimulation of the heart in 12 patients with various forms of tachycardia. Four subjects had electrocardiographic evidence of the WPW syndrome and episodes of circus movement tachycardia. Paroxysmal supraventricular tachycardia, confined to the atrioventricular (AV) node, was found in 3 patients. In 2 cases, where a short PR interval was present, the main complaint was the occurrence of paroxysmal atrial fibrillation. In the remaining 3 instances, the arrhythmia consisted of slow ventricular tachycardia (1 case), supraventricular tachycardia of the focal type (1 case), and episodes of primary ventricular fibrillation, not related to acute myocardial ischaemia ( 1 case).

L 9394 injected intravenously was seen to lengthen the transnodal conduction time as well as the effective and functional refractory periods of the node. Similar effects were found on the retrograde VA pathway. The drug had no action on the infra-Hisian conduction system, on the refractory periods of ventricular muscle, or on the refractory periods of accessory bypasses.

The drug was injected during an episode of tachycardia in 6 cases with reproducible supraventricular re-entrant tachycardia. Three had a tachycardia circuit confined to the node. In those instances, the drug had beneficial effects (slowing and interruption of tachycardia, decrease or abolition of echo zone; loss of ability to induce tachycardia). In the other 3 cases, an accessory pathway was incorporated in the circuit. L 9394 interrupted the tachycardia in 2 instances (by anterograde AV block), but failed to protect all 3 patients against reinitiation of tachycardia by premature stimuli.

It is concluded that L 9394 does not share all the pharmacological properties of amiodarone and will not replace it in all its indications.

Amiodarone has been reported to be an effective antiarrhythmic agent for different types of arrhythmia (Coumel et al., 1974; Rosenbaum et al., 1974; Touboul et al., 1975; Rosenbaum et al., 1976; Wellens et al., 1976; Waleffe et al., 1978). Sideeffects however have limited wide acceptance of the drug in clinical practice (Geerts, 1971; Verin et al., 1971; Babel and Stangos, 1973; Pritchard et al., 1975; Burger et al., 1976). L 9394, a benzoylindolizine derivative, is a new substance which is chemically related to amiodarone (Fig. 1) (Charlier

${ }^{1}$ Research Fellow of the Calouste Gulbenkian Foundation, Lisbon, Portugal.

${ }^{2}$ This work was performed while H. J. J. Wellens was Chaire Franqui Professor at the University of Liège.

Received for publication 5 December 1977 et al., 1976, 1977). However, since L 9394 is not a carrier of iodine atoms, there are reasons to believe that the drug is likely to be devoid of at least some of the side-effects of amiodarone. We therefore decided to investigate the electrophysiological properties of $\mathrm{L} 9394$ in man.

\section{Subjects and methods}

Twelve patients were studied. Data on age, sex, and type of arrhythmia are given in Table 1.

After obtaining informed consent, 4 catheters were introduced into the femoral vein using the Seldinger technique. One quadripolar catheter was positioned high on the lateral wall of the right atrium: the two distal electrodes were used for stimulation and the proximal electrodes for re- 
L 9394<smiles>CCCCN(CCCC)CCOc1ccc(OCC2=C(CC)CC3C=CC=CN23)cc1</smiles><smiles>CCCOc1c(I)cc(OCc2c(C)oc3ccccc23)cc1OCCN(CC)CC</smiles>

Fig. 1 Chemical structure of $L 9394$ as compared with amiodarone.

Table 1 Clinical features

\begin{tabular}{rrrl}
\hline \multicolumn{2}{l}{ Case } \\
\multicolumn{3}{l}{ no. Age and sex } & \multicolumn{2}{l}{ Diagnosis } \\
\hline 1 & 20 & F & AVN RT \\
2 & 23 & F & AVN RT \\
3 & 38 & F & AVN RT \\
4 & 55 & M & Short PR + AF \\
5 & 27 & F & Intermittent WPW type A + CMT \\
6 & 34 & F & WPW type B + CMT \\
7 & 26 & M & WPW type A + CMT + AF \\
8 & 51 & M & WPW type B \\
9 & 18 & M & Short PR + AF \\
10 & 19 & M & Slow VT \\
11 & 56 & F & VF \\
12 & 22 & M & SVT (focal type) \\
\hline
\end{tabular}

AF, atrial fibrillation; AVN RT, AV nodal re-entrant tachycardia; CMT, circus movement tachycardia; VF, ventricular fibrillation; VT, ventricular tachycardia; SVT, supraventricular tachycardia; WPW, Wolff-Parkinson-White syndrome.

cording the intra-atrial electrogram. A bipolar catheter was placed close to the bundle of His to record the His bundle electrogram. The third (bipolar) catheter was positioned in the apex of the

right ventricle and was used for ventricular stimulation.

In 6 patients, in order to record a left atrial 윽 electrogram, a fourth quadripolar catheter was advanced into the coronary sinus or, through a patent foramen ovale, into the left atrial cavity.

Using the extrastimulus technique, the effective $\stackrel{\varrho}{2}$ refractory period of the right atrium, the effective $\vec{\theta}$ and functional refractory periods of the AV node, $\overparen{\theta}$ and the effective refractory period of the right ventricle and of the accessory pathway, when present, were measured. The zones of premature beat intervals resulting in atrial echoes or sustained tachycardia were carefully determined. The right ventricle was paced up to its effective refractory period. The pattern and refractory period of VA conduction were registered. Atrial and ventricular pacing were first done at rates slightly above the spontaneous rate, and thereafter at shorter cycle lengths.

Table 2 Effects of L 9394 on electrophysiological indices: comparison of control values with longest values observed after drug administration

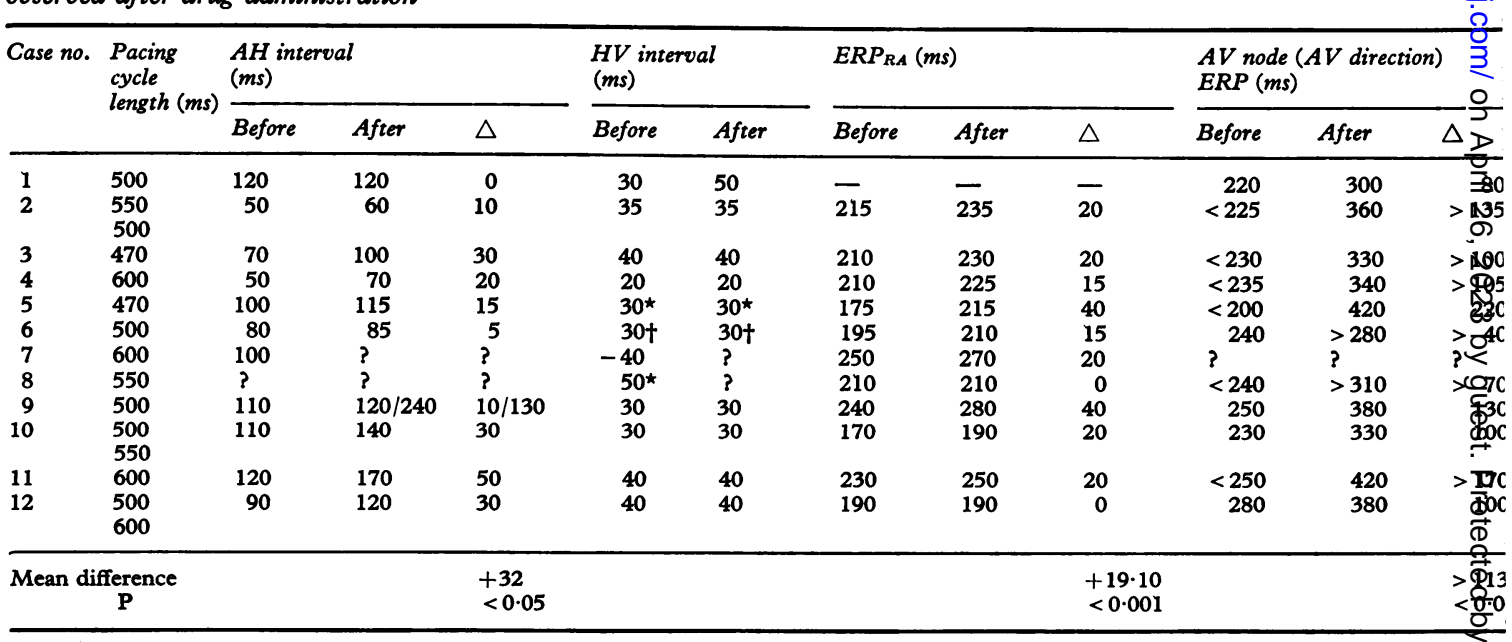

ERP, effective refractory period; FRP, functional refractory period; RA, right atrium; RV, right ventricle;

AP, accessory pathway. *Without pre-excitation; †During circus movement tachycardia. 
The various measurements were made before and after the injection of $2 \mathrm{mg} / \mathrm{kg}$ of $\mathrm{L}$ 9394, administered intravenously over a 5 -minute period. All measurements were repeated at the end of the injection (time zero) and again every fifteenth minute, during 1 hour.

All data obtained during the stimulation study were recorded on tape (HP $8868 \mathrm{~A}$ ) and directly registered on an eight-channel Elema Mingograf recorder. Leads I, II, III, V1, V6, the intracavitary right atrial lead, the left atrial lead (when available), and the His bundle electrogram were simultaneously recorded. For recording the His bundle electrogram, a 854 Universal Amplifier with input adapter was used.

The effective refractory period of the AV node was defined as the longest $\mathrm{A}_{1}-\mathrm{A}_{2}$ interval failing to conduct through the AV node. The functional refractory period (FRP) of the AV node was considered as the shortest $\mathrm{H}_{1}-\mathrm{H}_{2}$ interval that could be obtained. Since it was not always possible to determine when the AV node became refractory during ventricular pacing (because of absence of a retrograde $\mathrm{H}$ potential and/or because of a gap phenomenon in VA conduction), no values will be given for the effective refractory period of the different parts of the VA conduction system. Statistical analysis was performed using the paired $t$ test. Plasma levels of L 9394 were determined by using a chromatographic method (J. Broekhuysen, 1977, personal communication).

\section{Results}

The results are summarised in Table 2.

\section{AV CONDUCTION}

As indicated in the Table, the AH interval lengthened after the L 9394 injection in all but 1 of the 10 patients in whom it could be measured. Mean increase in $\mathrm{AH}$ interval was $32 \mathrm{~ms}$ (range 0 to 130 $\mathrm{ms})(\mathbf{P}<0.05)$. In case 9, a sudden and distinct lengthening of the $\mathrm{AH}$ interval (jump from 120 to $240 \mathrm{~ms}$ ) was transiently observed 30 minutes after the administration of $\mathrm{L} 9394$.

Because some patients had the WPW syndrome, the refractory periods of the AV node could not be measured in all studies. The effective refractory period measured in 11 patients increased by an average of more than $113.6 \mathrm{~ms}(P<0.001)$. The functional refractory period increased by an average of more than $89.4 \mathrm{~ms}(\mathrm{P}<0.001)$.

A pattern suggestive of a dual AV nodal pathway was present before L 9394 administration in 2 patients (cases 1 and 9). L 9394 did not alter the broken aspect of the AV conduction curve in case 9, the electrophysiological properties of both pathways being similarly affected by the drug. But in case 1 , a smooth curve was observed during the initial 20 minutes after drug injection. In 2 patients (cases 3 and 5), the injection of L 9394 revealed a dual AV nodal pathway curve that had not been depicted before drug administration. In case 5, this dual pathway curve appeared 20 minutes after injection and persisted until the end of the investigation. In case 2 , a patient with AV nodal re-entrant tachycardia, a smooth AV conduction curve was consistently obtained both before and after the administration of L 9394.

In patients without pre-excitation no change was observed in the HV interval.

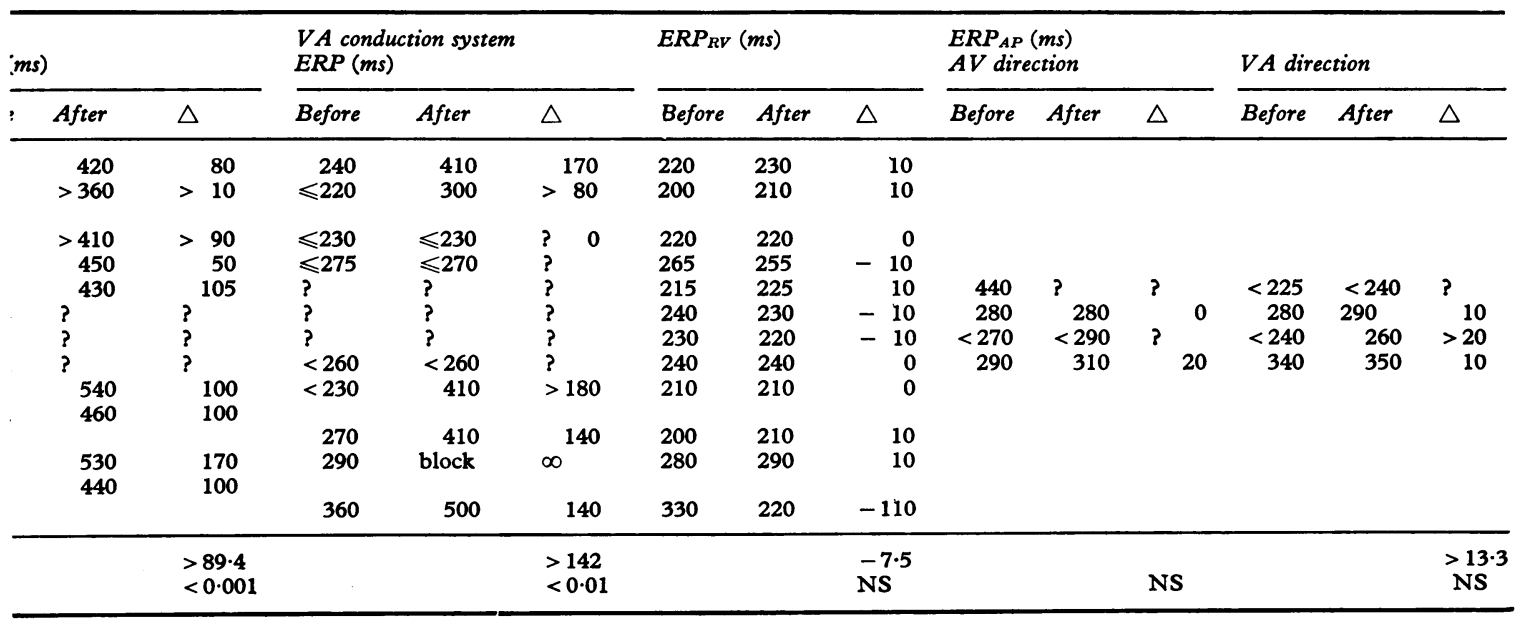


Table 3 Effects of L 9394 on tachycardia

\begin{tabular}{|c|c|c|c|c|c|c|c|c|}
\hline \multirow[t]{2}{*}{ Case no. } & \multirow[t]{2}{*}{$C L$} & \multirow[t]{2}{*}{ Tachycardia type } & \multicolumn{2}{|l|}{ Initiation } & \multicolumn{2}{|c|}{$\begin{array}{l}\text { Tachycardia zone } \\
\text { (ms) }\end{array}$} & \multicolumn{2}{|c|}{$\begin{array}{l}R R \text { interval during } \\
\text { tachycardia (ms) }\end{array}$} \\
\hline & & & Before & After & Before & After & Before & After \\
\hline 1 & $\begin{array}{l}500 \\
500\end{array}$ & $\begin{array}{l}\text { AVN RT } \\
\text { AF }\end{array}$ & $\begin{array}{l}1 \mathrm{APB} \\
1 \mathrm{APB}\end{array}$ & - & $\begin{array}{l}250-230 \\
210-180\end{array}$ & - & $\begin{array}{l}360 \\
400\end{array}$ & - \\
\hline 2 & 300 & AVN RT & Rapid atrial pacing & - & & & 330 & $\overline{-}$ \\
\hline & 300 & $A V N R T$ & $\begin{array}{l}\text { Rapid ventricular } \\
\text { pacing }\end{array}$ & - & & & 330 & - \\
\hline 3 & $\begin{array}{l}\text { SR } \\
270\end{array}$ & AVN RT & $\begin{array}{l}2 \mathrm{APB} 3 \mathrm{APB} \\
\text { rapid atrial pacing }\end{array}$ & - & & & 310 & - \\
\hline 5 & $\begin{array}{l}470 \\
470 \\
290\end{array}$ & CMT (WPW) & $\begin{array}{l}2 \text { APB } \\
3 \text { VPB } \\
\text { rapid atrial pacing }\end{array}$ & $\begin{array}{l}1 \mathrm{APB} \\
1 \mathrm{VPB} \\
-\end{array}$ & & $\left.\begin{array}{l}320-265 \\
390-300\end{array}\right\}$ & $290-380$ & 450 \\
\hline 6 & $\begin{array}{l}500 \\
500\end{array}$ & CMT (WPW) & $1 \mathrm{APB}$ & $\overline{1}$ & $280-255$ & $\overline{290}$ & 300 & 390 \\
\hline 7 & 600 & CMT (WPW) & 1 VPB & 1 VPB & $\overline{310}-300$ & $\begin{array}{l}290 \\
350\end{array}$ & $320-360$ & 450 \\
\hline
\end{tabular}

CL, cycle length; AVN RT, AV nodal re-entrant tachycardia; AF, atrial flutter; CMT, circus movement tachycardia; APB, atrial premature $\mathrm{O}$ beat; VPB, ventricular premature beat; SR, sinus rhythm.

VA CONDUCTION

In 3 patients (cases $5,6,7$ ), the presence of an accessory pathway (with an effective refractory period in VA direction shorter than that of the ventriculoatrial conducting system) did not permit accurate evaluation of changes in VA conduction characteristics through the His AV nodal axis.

In 3 patients (cases $3,4,8$ ), VA conduction per- $\stackrel{\varrho}{=}$ sisted after drug administration up to the functional refractory period of the ventricle.

In 1 patient, after L 9394, a complete VA block. occurred (case 11). Finally, in the remaining 5

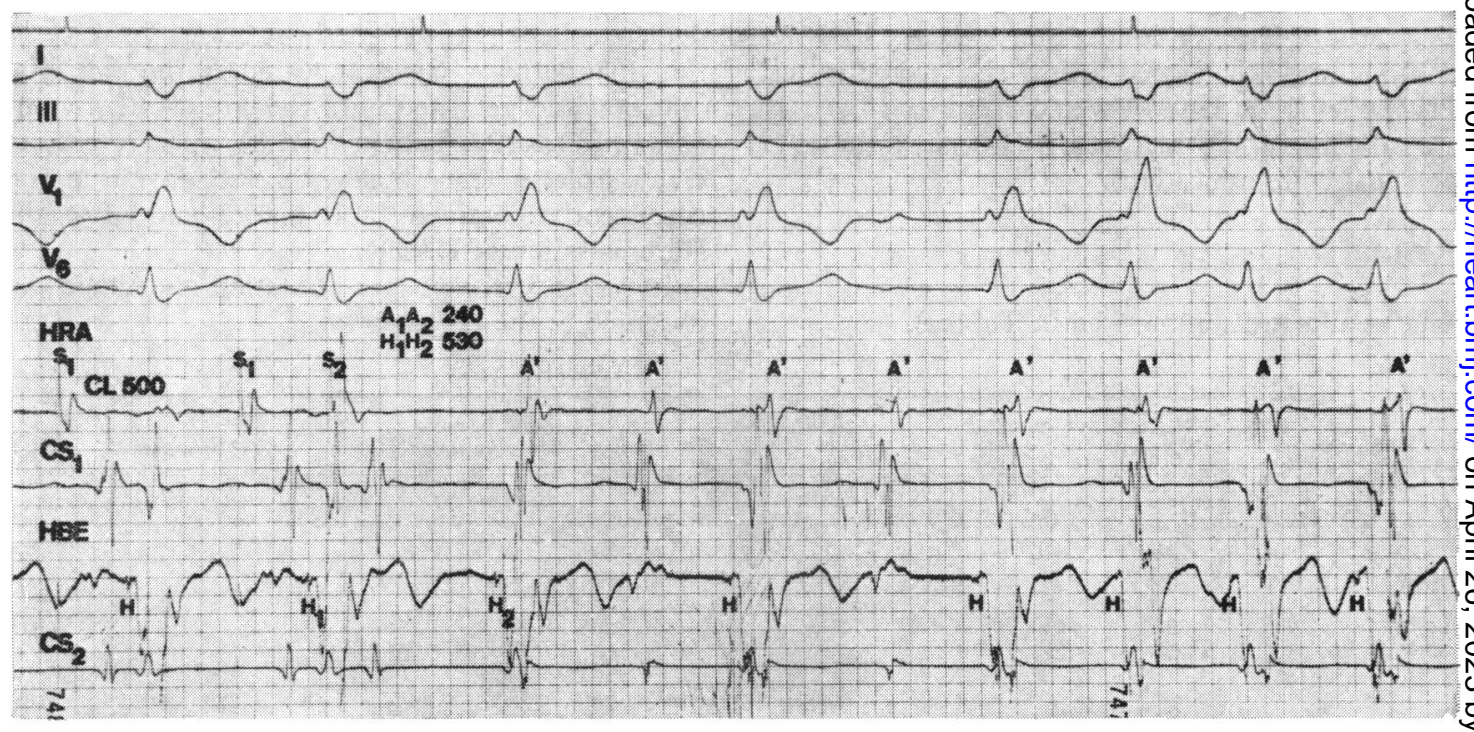

Fig. 2(a)

Fig. 2 Case 1. Eight leads are simultaneously recorded: I, III, V1,V6, HRA (high right atrial lead), $C S_{1}$ and $C S_{\mathrm{z}}$ (two coronary sinus leads), and the HBE (His bundle electrogram).

In (a) before drug administration, at a $A_{1} A_{2}$ interval of $240 \mathrm{~ms}$, a long $A H$ interval is observed $\left(H_{1} H_{2}=530 \mathrm{~ms}\right)$ and an episode of $A V$ nodal re-entrant tachycardia (with transient 2:1 $\mathrm{AV}$ block) is initiated.

In (b) and (c) after administration of $L$ 9394, a jump in the curve plotting the $H_{1} H_{2}$ intervals against the $A_{1} A_{2}$ intervals is still observed $\left(H_{1} H_{2}\right.$ equals $410 \mathrm{~ms}$ for an $A_{1} A_{2}$ of $350 \mathrm{~ms}$, and $550 \mathrm{~ms}$ for an $A_{1} A_{2}$ of $\left.340 \mathrm{~ms}\right)$. In spite of this, no echo beat or tachycardia is elicited, the fast conducting pathway being now blocked in the retrograde direction. 

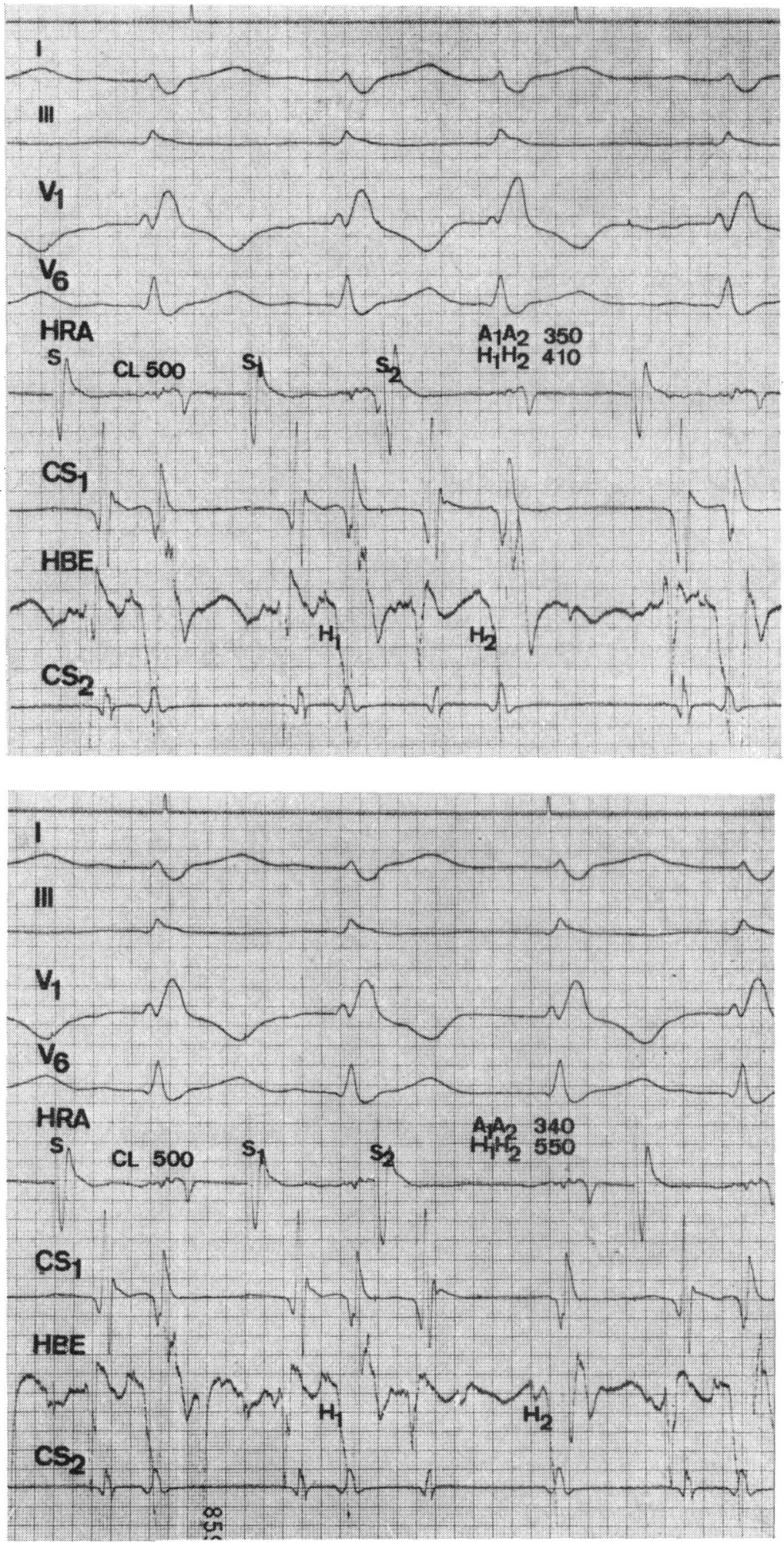

Fig. 2(c)

Fig. 2(b) 


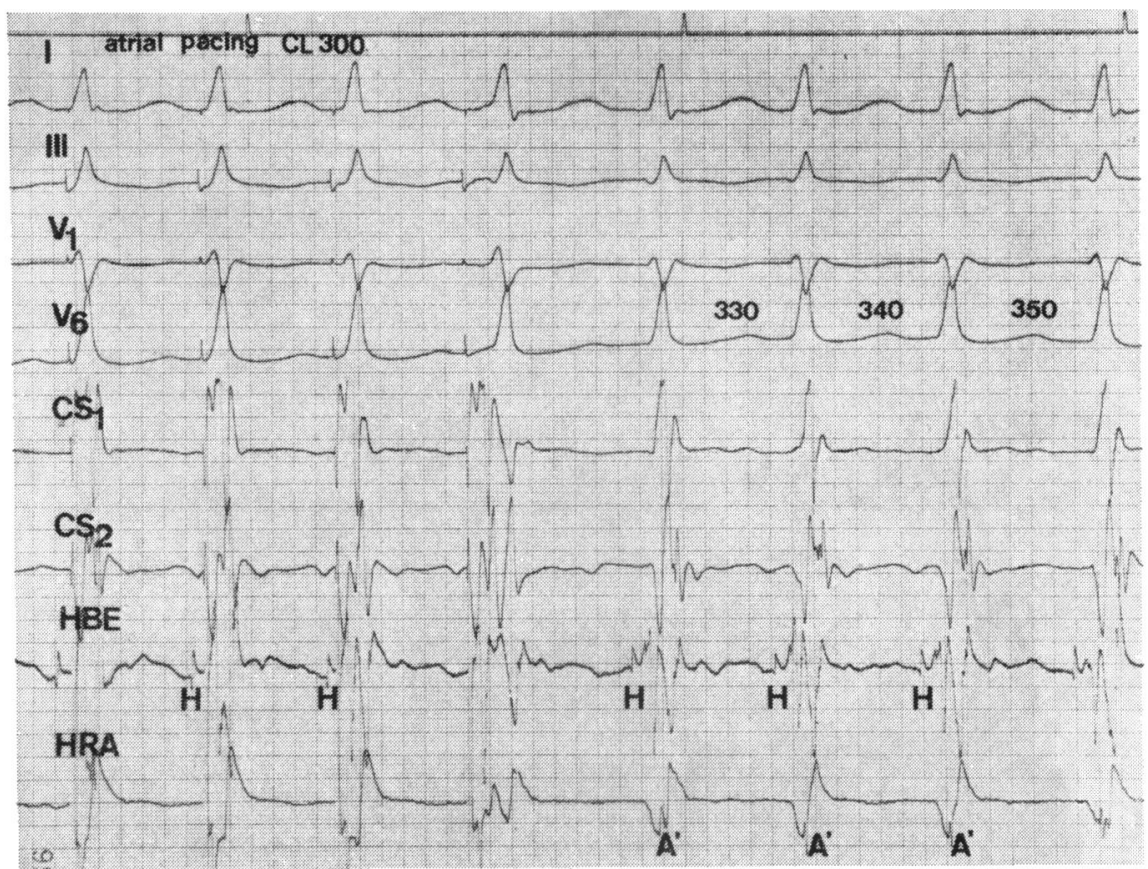

Fig. 3(a)

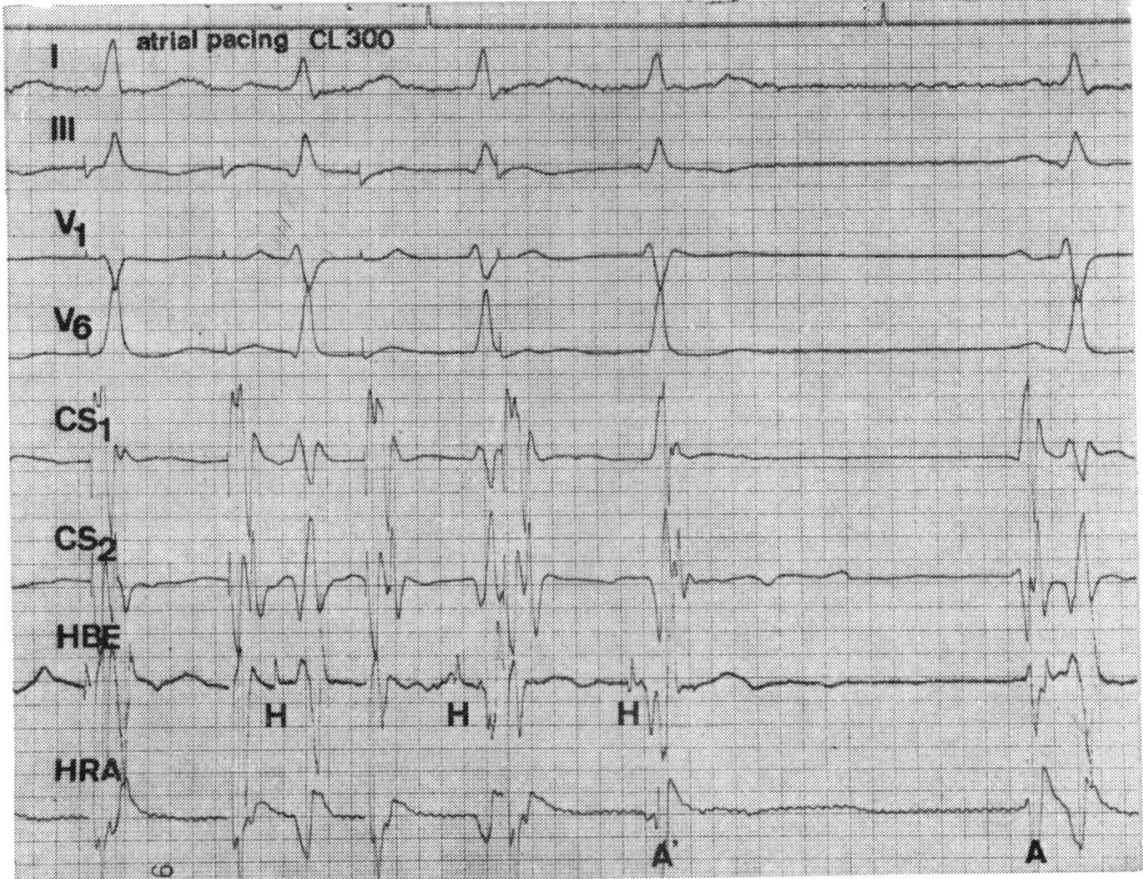

Fig. 3(b)

Fig. 3 Case 2. (a) Before drug administration, atrial pacing at a cycle length of $300 \mathrm{~ms}$ results in a Wenckebach type of response and its interruption is followed by the initiation of an episode of tachycardia ( $A V$ nodal re-entrant tachycardia). (b) After administration of $L$ 9394, the Wenckebach type of block is more obvious during atrial pacing. After interruption of pacing, one AV nodal re-entry cycle is completed, but this is not followed by tachycardia, the slow conducting pathway being now blocked in the anterograde direction. 
subjects (cases $1,2,9,10,12$ ), the effective refractory period of the VA conduction system lengthened by an average of at least $142 \mathrm{~ms}$.

\section{EFFECTIVE REFRACTORY PERIOD OF RA} AND RV

In all but 2 cases, the ERP of the right atrium slightly lengthened. The changes were statistically significant $(P<0.001)$ but, in absolute values, they appeared trivial. The ERP of the right ventricle failed to show any consistent alteration.

\section{ERP OF ACCESSORY PATHWAY}

An accessory pathway was present in 4 cases ( 2 right-sided; 2 left-sided). The drug was found to have no effect on its effective refractory period either in anterograde or retrograde direction.

\section{MECHANISM OF TACHYCARDIA}

In the 3 patients with AV nodal re-entrant tachycardia (cases 1 to 3 ), and in 3 of the 4 subjects with WPW (cases 5 to 7), episodes of tachycardia could be initiated by electrical stimulation (Table 3 ).

In case 1 (Fig. 2), before the administration of the drug, a single atrial extrastimulus $\left(S_{2}\right)$ delivered between 250 and $230 \mathrm{~ms}$ after the preceding stimulus $\left(S_{1}\right)$ initiated an AV nodal re-entrant tachycardia with a cycle length of $360 \mathrm{~ms}$. In addition, $S_{2}$ stimuli, delivered from $210 \mathrm{~ms}$ to $180 \mathrm{~ms}$ after $S_{1}$, started episodes of atrial flutter with a ventricular cycle length of $400 \mathrm{~ms}$. After L 9394 administration, the jump in the curve plotting the $\mathrm{H}_{1} \mathrm{H}_{2}$ against the $A_{1} A_{2}$ intervals transiently disappeared; it was again observed after a 20 -minute period; extrastimuli however could induce only one or two reentrant echo beats, but no sustained tachycardia. Atrial flutter could not be elicited.

In case $2, \mathrm{AV}$ nodal re-entrant tachycardia could be started only by rapid atrial or ventricular pacing (Fig. 3). After L 9394, no tachycardia could be induced.

In case 3, supraventricular tachycardia could be initiated by 2 or 3 atrial extrastimuli or by rapid atrial pacing. After drug administration, the ability to induce tachycardia was lost in spite of the unmasking effect of a previously concealed dual AV nodal pathway.

In case 5 (Fig. 4), a left-sided accessory pathway was associated with a dual AV nodal pathway curve unmasked by L 9394 injection. Episodes of tachycardia with two different cardiac rates (suggesting circuits with $\mathrm{AV}$ conduction over either the fast, or the slow AV nodal pathway, and VA conduction over the accessory pathway) could be initiated before drug administration by giving a salvo of at least 3 ventricular extrastimuli, more rarely by 2 atrial premature beats, or by rapid atrial pacing at a rate producing a Wenckebach phenomenon. After the drug, a jump in the AV conduction curve became clearly apparent. Initiation and termination of tachycardia were facilitated. Circus movement tachycardia, using the accessory pathway retrogradely, could be started by either a single ventricular or atrial premature beat with relatively large tachycardia zones (at that time the fast AV nodal pathway had become refractory), by rapid atrial pacing at rates producing a second degree AV block, and by ventricular pacing. The tachycardia could easily be terminated by 2 ventricular premature beats and, with greater difficulty, by a single ventricular extrastimulus, or by 3 atrial premature beats. The tachycardia cycle length was significantly prolonged after L $9394(410 \mathrm{~ms}$ as compared with 290 or 380 before the injection), this lengthening being in part the result of the exclusive use of the slow AV nodal pathway for anterograde conduction.

In 6 patients with reproducible paroxysmal re-entrant tachycardias, L 9394 was administered during an episode of tachycardia. The injection resulted in termination of the rhythm disorder in all patients with the intranodal type of tachycardia and in 2 of the 3 cases with the WPW syndrome (cases 5 and 7). The heart rate during tachycardia decreased in each subject; this was related to slowing of conduction along the AV node and not to prolongation of the VA conduction time.

\section{OTHER INDICES}

Sinus node function tests were not performed during this investigation because of a lack of time during the procedure.

In 2 of the cases, the threshold for atrial stimulation was noted to increase after L 9394 administration. In case 9 , for example, the threshold at the end of injection rose to $20 \mathrm{~mA}$. This value was 5 times greater than the control value. It fell to $7 \mathrm{~mA} 22$ minutes later and to $5 \mathrm{~mA}$ after 30 minutes. In case 2 , the threshold was measured at $7 \mathrm{~mA}$ at the end of the injection and at $4 \mathrm{~mA} 30$ minutes later.

In the remaining subjects, no attempt was made to measure systematically the threshold for atrial stimulation. Since stimulation was done at twice the threshold value, any increase of less than 100 per cent would have passed unnoticed.

Arterial blood pressure was monitored throughout the study, in 4 cases by continuous intraarterial pressure recording, and in the remaining instances by repeated measurements by sphygmomanometer. No significant change was observed.

The plasma level of $\mathrm{L} 9394$ was $3.0 \mathrm{ng} / \mathrm{ml} \pm 2.0$ at the end of injection and $0.47 \pm 0.2115$ minutes 
later. After the end of injection, the plasma levels showed an exponential decrease. No correlation was observed between the pharmacological effects and the plasma levels of the drug during this initial distribution period (Wellens and Durrer, 1974).

\section{Discussion}

The results of our investigation show that L 9394 is a substance which acts mainly on the AV node. It lengthens the transnodal conduction time as well as the effective and functional refractory periods of the node. As opposed to amiodarone (Touboul et al., 1975; Wellens et al., 1976; Waleffe et al., 1978), it has no effect on anterograde conduction over the intraventricular conduction system, on ventricular muscle, and accessory pathways.

The observed changes are of the same order of magnitude as those which have been reported previously with ouabain (Wellens et al., 1975; Wu et al., 1975), propranolol (Wu et al., 1974), and verapamil (Wellens et al., 1977).

In contrast to verapamil (Wellens et al., 1977), L 9394 had some effect on the retrograde VA pathway in several patients. This may of course reflect an action on the AV node but functional changes within the His-Purkinje system used retrogradely cannot be ruled out.

Our observations indicate that L 9394 is a potentially interesting drug for the treatment of tachycardias confined to the AV node. In the 3 patients whom we studied, the episodes of tachycardia were ended by the intravenous injection of the drug. In addition, L 9394 decreased or totally eliminated the echo zones and made the patients lose their ability to develop sustained paroxysmal $\ddot{\vec{F}}$

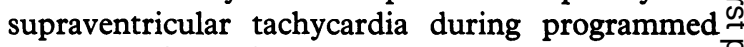
electrical stimulation.

The effects in patients with circus movement $\frac{\bar{\sigma}}{\bar{c}}$ tachycardia associated with pre-excitation are less $\underset{\widetilde{\sigma}}{\vec{\sigma}}$ clear. In the 3 patients studied, the drug produced $\bigcirc$ slowing of transmission through the anterograde $\tilde{D}^{\circ}$ AV nodal part of the tachycardia circuit which $\vec{\circ}$ resulted in a significant slowing of the cardiac rate $\vec{\overrightarrow{ }}$ during circus movement tachycardia. L $9394 \stackrel{\omega}{\omega}$ interrupted tachycardia in 2 instances, but failed to protect all 3 patients against reinitiation of tachycardia by premature stimuli. These observations. resemble those made in patients with concealed $\vec{\infty}$ bypasses after administration of ouabain (Wellens 0 et al., 1975; Wu et al., 1975), propranolol (Wu et al., 은 1974), and verapamil (Wellens et al., 1977). As $\vec{c}$ pointed out by others (Wellens et al., 1975; Wu et al., 1975), by producing selective slowing of conduction within the AV node, these drugs, like L 9394, may actually favour the initiation and perpetuation of $\vec{\varphi}$ circus movement tachycardia in the presence of a ventriculoatrial accessory pathway. Delaying conduction through the node increases the chance for a premature impulse to reach the ventricular end of the bypass when it is excitable and thus promotes VA conduction over this pathway and initiation as $\frac{0}{\circ}$ well as perpetuation of tachycardia. This was clearly shown in case 5 of this series in whom an $\overline{\overrightarrow{0}}$ accessory bypass as well as a dual nodal pathway were simultaneously present. Prolongation of the conduction time especially along the slow nodal pathway made it much easier to induce the tachycardia after drug administration.

Drug induced changes of the pattern of atrioventricular conduction have previously been re-

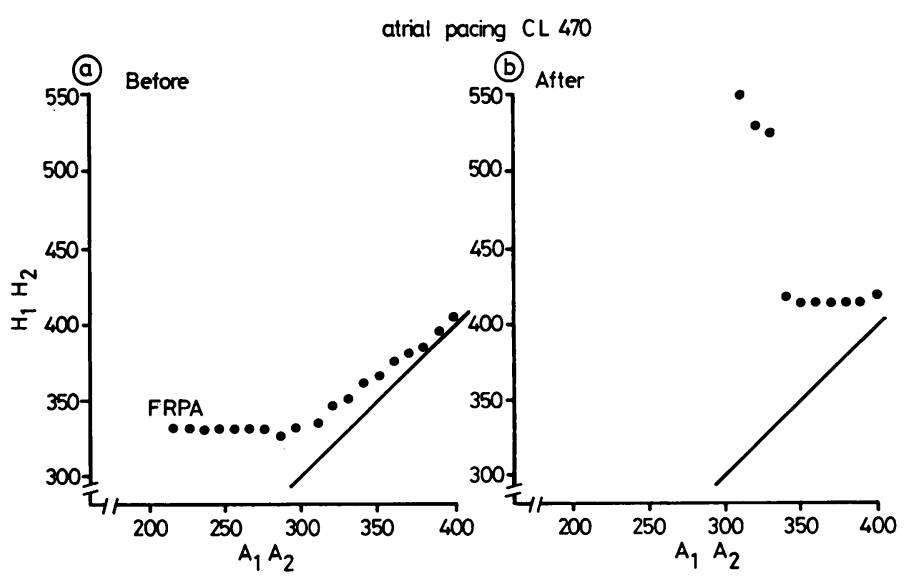

Fig. 4(a) 
Before L 9394
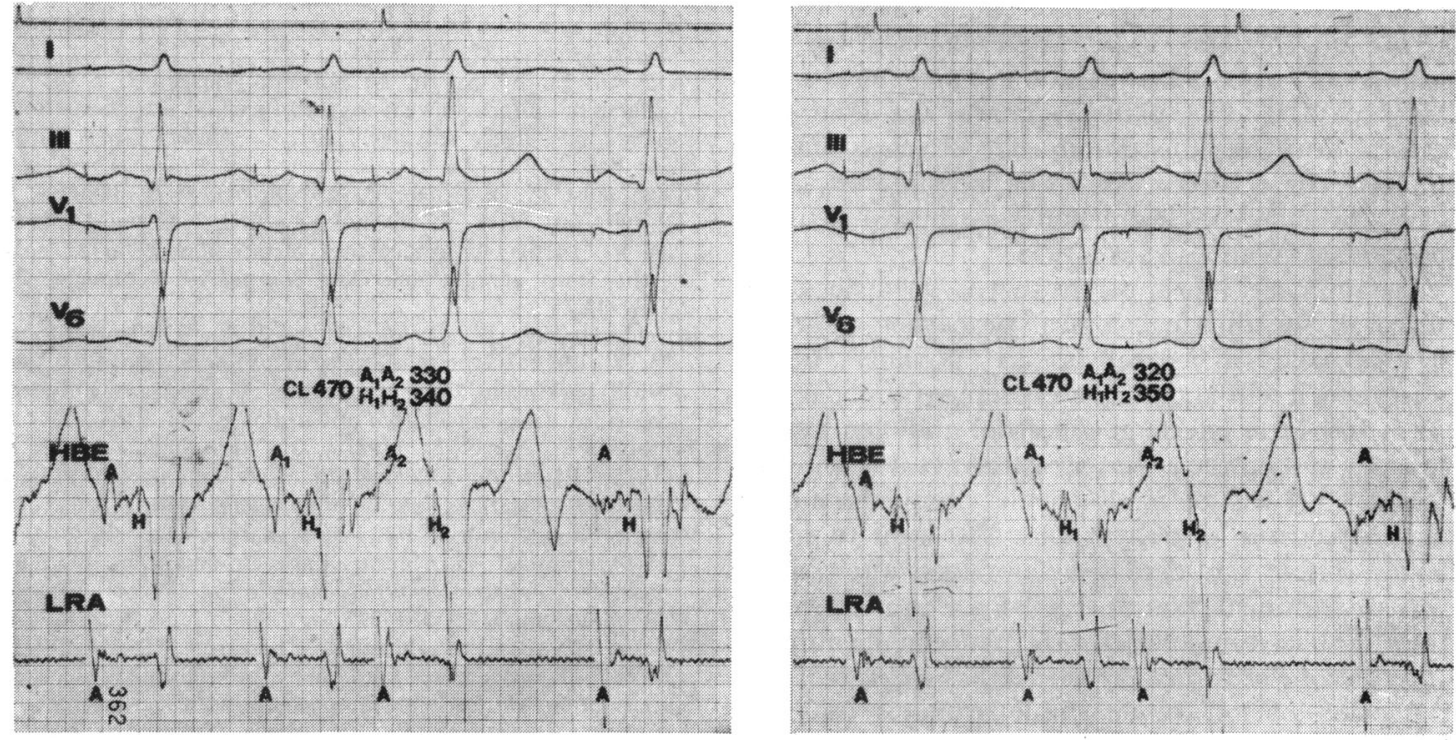

Fig. 4(b)

\section{After L.9394}
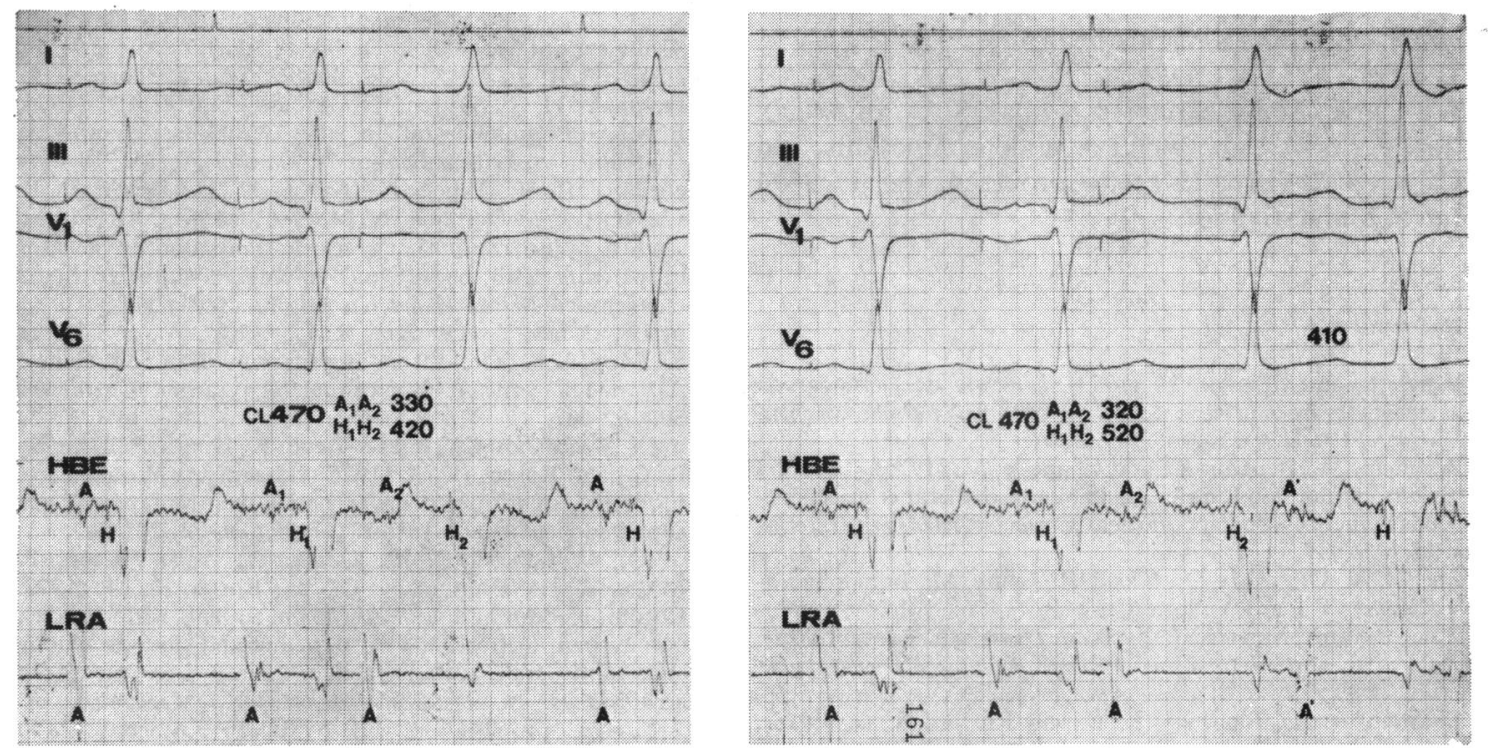

Fig. 4(c)

Fig. 4 Case 5. (a) The curve plotting the $\mathrm{H}_{1} \mathrm{H}_{2}$ against the $A_{1} A_{2}$ intervals is smooth in the control state, but shows after administration of $L 9394$ a typical jump at 320 ms. Tracings were obtained before (b) and after (c) administration of the drug. Before $L 9394$ (b) single ectopic beats elicited at $A_{1} A_{2}$ intervals of 330 and 320 ms failed to initiate tachycardia. After L9394 (c) the ectopic beat elicited at an $A_{1} A_{2}$ interval of 320 ms produced a sudden increase of the AH time and initiated an episode of tachycardia with a longer cycle length (410 ms) than in the basic conditions (290 to $380 \mathrm{~ms}$ ). LRA: low right atrial lead. 
ported (Wu et al., 1974; Wellens et al., 1975, 1977). Two different situations were encountered in this series. In 2 patients, a dual AV nodal pathway was shown only after administration of L 9394. In one other case, a dual pathway curve was identified before drug administration, but changed into a smooth curve afterwards. The possible explanations for such a phenomenon have been discussed previously (Wellens et al., 1975).

In summary, it is apparent that L 9394 does not share all the pharmacological properties of amiodarone and in spite of its possibly better tolerance, it will not completely replace amiodarone. As it has little effect on the atrial and ventricular muscles and on the accessory pathways it is unlikely that L 9394 will be as effective as amiodarone on a large spectrum of arrhythmias. We want to stress however that our data were obtained after intravenous administration of $\mathrm{L} 9394$. Little is known of the pharmacokinetics of this substance in the human. In addition, previous experience has indicated that the effect of intravenous amiodarone is different from that obtained after long-term oral administration (Berkman et al., 1975). In view of this, chronic studies (Wu et al., 1977) on the effect of L 9394 administered orally are needed before any definite conclusion can be drawn regarding the clinical usefulness of this drug.

We thank Mr Broekhuysen (Labaz S.A., Brussels), who performed the blood level determinations, and Labaz S.A. (Brussels) who provided the L 9394 for this investigation.

\section{References}

Babel, J., and Stangos, N. (1973). L'action de l'amiodarone sur les tissus oculaires. Schweizerische medizinische Wochenschrift, 102, 220-223.

Berkman, M., Benaim, R., and Chapelle, M. (1975). Troubles de la conduction induits par l'amiodarone oral et injectable, conséquences thérapeutiques. Coeur et Médecine Interne, 14, 439-447.

Burger, A., Dinichert, D., Nicod, P., Jenny, M., LemarchandBéraud, T., and Vallotton, M. B. (1976). Effect of amiodarone on serum triiodothyronine, reverse triiodothyronine, thyroxin and thyrotropin. Fournal of Clinical Investigation, 58, 255-259.

Charlier, R. H., Bauthier, J. A., and Richard, J. C. (1976). An indolizine with an amiodarone-like haemodynamic profile (abstract). British fournal of Pharmacology, 58, $411 \mathrm{P}-412$.

Charlier, R., Bauthier, J., and Richard, J. (1977). Propriétés antiarythmiques d'une benzoyl-indolizine. Fournal de Pharmacologie, 8, 361-372.

Coumel, Ph., Fidelle, J., Cloup, M., Toumieux, M. C., and Attuel, P. (1974). Les tachycardies réciproques à évolution prolongée chez l'enfant. Archives des Maladies du Coeur et des Vaisseaux, 67, 23-38.

Geerts, M. L. (1971). Amiodarone pigmentation. An electron microscopic study. Archives Belges de Dermatologie et de으 Syphiligraphie, 27, 339-351.

Pritchard, D. A., Singh, B. N., and Hurley, P. J. (1975). Effects of amiodarone on thyroid function in patients with $\vec{T}$ ischaemic heart disease. British Heart fournal, 37, 856-860.

Rosenbaum, M. B., Chiale, P. A., Halpern, M. S., Nau, G. J., Przybylski, R. J., Levi, R. J., Lazzari, J. O., and Elizari, $\vec{O}$ M. V. (1976). Clinical efficacy of amiodarone as an antiarrhythmic agent. American fournal of Cardiology, 38, $\vec{\omega}$ 934-944.

Rosenbaum, M. B., Chiale, P. A., Rijba, D., and Elizari, M. V. (1974). Control of tachyarrhythmias associated with Wolff-Parkinson-White syndrome by amiodarone hydro- $\rightarrow$ chloride. American fournal of Cardiology, 34, 215-223.

Touboul, P., Porte, J., Huerta, F., and Delahaye, J. P. (1975). Electrophysiological effects of amiodarone in man $\mathrm{O}$ (abstract). American fournal of Cardiology, 35, 173.

Verin, Ph., Gendre, Ph., and Barchewitz, G. (1971). $\overrightarrow{-}$ Thésaurismose cornéenne par amiodarone. Données ఏ récentes. Archives d'Ophtalmologie et Revue Générale d'Ophtalmologie, 31, 581-595.

Waleffe, A., Bruninx, P., and Kulbertus, H. E. (1978). Effects of amiodarone studied by programmed electrical $\vec{\theta}$ stimulation of the heart in patients with paroxysmal reentrant supraventricular tachycardia. Fournal of Electro-. cardiology, 11, 253-260.

Wellens, H. J. J., Düren, D. R., Liem, K. L., and Lie, K. I. O (1975). Effect of digitalis in patients with paroxysmal atrioventricular nodal tachycardia. Circulation, 52, 779-788. $\overline{\mathrm{O}}$

Wellens, H. J. J., and Durrer, D. (1974). Effect of procaineڤ

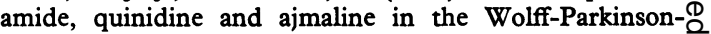
White syndrome. Circulation, 50, 114-120.

Wellens, H. J. J., Lie, K. I., Bär, F. W., Wesdorp, J. C.,으 Dohmen, H. J., Düren, D. R., and Durrer, D. (1976). Effects of amiodarone in the Wolff-Parkinson-White? syndrome. American fournal of Cardiology, 38, 189-194.O

Wellens, J. H. H., Tan, S. L., Bär, F. W. H., Düren, D. R., ᄀ Lie, K. I., and Dohmen, H. M. (1977). Effect of verapamili studied by programmed electrical stimulation of the heart in patients with paroxysmal re-entrant supraventricularo tachycardia. British Heart fournal, 39, 1058-1066.

Wu, D., Denes, P., Dhingra, R. C., Khan, A., and Rosen, K. M. (1974). The effects of propranolol on induction of A-V nodal reentrant paroxysmal tachycardia. Circulation, 50, 665-667.

Wu, D., Wyndham, C., Amat-y-Leon, F., Denes, P., Dhingra, R. C., and Rosen, K. M. (1975). The effects of ouabain on induction of atrioventricular nodal reentrant paroxysmale. supraventricular tachycardia. Circulation, 52, 201-207. N

Wu, D., Wyndham, C. R., Denes, P., Amat-y-Leon, F.) Millet, R. H., Dhingra, R. C., and Rosen, K. M. (1977) № Chronic electrophysiological study in patients with recurrentu paroxysmal tachycardia: a new method for developing successful oral antiarrhythmic therapy in re-entrank arrhythmias. In Reentrant Arrhythmias, Mechanisms ando Treatment, pp. 294-311. Ed. by H. E. Kulbertus. MTP Press, Lancaster.

Requests for reprints to Professor Henri Kulbertus Division of Cardiology, Institute of Medicine $\stackrel{\vec{D}}{\mathrm{D}}$ University of Liège School of Medicine, $66 \mathrm{Bvd}$ de la Constitution, B-4020 Liège, Belgium. 